\title{
Isoindolone derivative QSN-10c induces leukemic cell apoptosis and suppresses angiogenesis via PI3K/AKT signaling pathway inhibition
}

\author{
Wen-wen LV ${ }^{1,2}$, Si-ning QIN² , Cong-qin $\mathrm{CHEN}^{2}$, Jin-jie ZHANG ${ }^{2}$, Tian-shu REN ${ }^{1}$, Yong-nan $\mathrm{XU}^{2, *}$, Qing-chun ZHAO ${ }^{1, *}$ \\ ${ }^{1}$ Department of Pharmacy, General Hospital of Shenyang Military Area Command, Shenyang 110840, China; ${ }^{2}$ Shenyang \\ Pharmaceutical University, Shenyang 110016, China
}

Aim: 2-(4,6-Dimethoxy-1,3-dioxoisoindolin-2-yl) ethyl 2-chloroacetate (QSN-10c) is one of isoindolone derivatives with antiproliferative activity against human umbilical vein endothelial cells (HUVECs). The aim of this study was to investigate its antitumor activity in vitro and anti-angiogenic effects in vitro and in vivo.

Methods: K562 leukemic cells and HUVECs were used for in vitro studies. Cell viability was examined using MTT assay. Cell apoptosis and mitochondrial transmembrane potential $(\Delta \psi \mathrm{m})$ were detected with flow cytometry. Tube formation and migration of HUVECs were studied using two-dimensional Matrigel assay and wound-healing migration assay, respectively. VEGF levels were analyzed with RT-PCR and Western blotting. A zebrafish embryo model was used for in vivo anti-angiogenic studies. The molecular mechanisms for apoptosis in K562 cells and antiangiogenesis were measured with Western blotting.

Results: In antitumor activity studies, QSN-10c suppressed the viability of K562 cells and induced apoptosis in dose- and timedependent manners. Furthermore, QSN-10c dose-dependently decreased the $\Delta \psi \mathrm{m}$ in K562 cells, increased the release of cytochrome $c$ and the level of Bax, and decreased the level of Bcl-2, suggesting that QSN-10c-induced apoptosis of K562 cells was mediated via the mitochondrial apoptotic pathway. In anti-angiogenic activity studies, QSN-10c suppressed the viability of HUVECs and induced apoptosis in dose dependent manners. QSN-10c treatment did not alter the $\Delta \Psi \mathrm{m}$ in HUVECs, but dose-dependently inhibited the expression of VEGF, inhibited the tube formation and cell migration in vitro, and significantly suppressed the number of ISVs in zebrafish embryos in vivo. Furthermore, QSN-10c dose-dependently suppressed the phosphorylation of AKT and GSK3 $\beta$ in both HUVECs and K562 cells.

Conclusion: QSN-10c is a novel antitumor compound that exerts both antitumor and anti-angiogenic effects via inhibiting the PI3K/ AKT/GSK3 $\beta$ signaling pathway.

Keywords: isoindolone; anticancer drug; leukemia; zebrafish; angiogenesis; apoptosis; AKT; GSK3 $\beta$

Acta Pharmacologica Sinica (2014) 35: 625-635; doi: 10.1038/aps.2013.194

\section{Introduction}

Angiogenesis, the formation of new blood vessels from preexisting vasculature, occurs under a variety of physiological and pathological conditions. Accumulating evidence indicates that angiogenesis is especially critical for the growth and progression of solid tumors. The growth of a tumor mass beyond 2 to $3 \mathrm{~mm}^{3}$ is often preceded by increased formation of new blood vessels essential for the delivery of nutrients and oxygen as well as the removal of metabolic waste from the tumor microenvironment ${ }^{[1,2]}$. Moreover, many recent stud-

\footnotetext{
* To whom correspondence should be addressed.

E-mail zhaoqingchun1967@163.com (Qing-chun ZHAO); ynxucn@syphu.edu.cn (Yong-nan XU)

Received 2013-09-10 Accepted 2013-12-19
}

ies have demonstrated the important role of angiogenesis in hematologic neoplasms ${ }^{[3-5]}$. Therefore, anti-angiogenic and angio-prevention therapies represent promising approaches to control tumor growth and metastasis ${ }^{[6,7]}$. Neoangiogenesis is a highly ordered, multistep molecular process tightly regulated in endothelial cells ${ }^{[8,9]}$ that involves the proliferation of endothelial cells (ECs), motility, cell realignment, vessel formation, and the production of a new basement membrane ${ }^{[1,10,11]}$. Of the numerous growth factors and cytokines that have been shown to possess angiogenic effects, vascular endothelial growth factor (VEGF) is an attractive therapeutic target for the development of novel anticancer agents ${ }^{[12]}$. VEGF is produced in tumor and vascular cells, thus stimulating angiogenesis through an autocrine fashion ${ }^{[13]}$. The inhibition of VEGF expression in endothelial cells contributes to reduced 
angiogenesis in HUVECs. In endothelial cells, VEGF has been shown to exert mitogenic activities and vasopermeability responses primarily through VEGFR-2 ${ }^{[14]}$, thereby promoting endothelial cells proliferation and migration via increased phosphorylation of extracellular signal-regulated kinase 1/2 (ERK1/2) (proliferation), phosphorylated-serine/threonine protein kinase family protein kinase B (AKT) (migration and survival), and c-Jun N-terminal kinase (JNK) (vascular permeability) ${ }^{[15-18]}$.

In our search for tumor inhibitors from natural sources, we identified 4,6-dihydroxyisoindol-1,3-dione (Figure 1) as a new compound isolated from Lasiosphaera fenzlii Reich. Our previous studies demonstrated that this compound has enhanced anti-angiogenic activity compared with thalidomide via inhibition of VEGF secretion. However, the compound exhibits only a slight inhibitory effect on tumor cell proliferation ${ }^{[19]}$. To find a compound with antitumor and anti-angiogenic activities in vitro, a series of isoindolone derivatives were subsequently synthesized, and their cytotoxicities were preliminarily evaluated in A549 and HUVEC cells. A new compound, 2-(4,6-dimethoxy-1,3-dioxoisoindolin-2-yl) ethyl 2-chloroacetate (QSN-10c, Figure 1), demonstrated moderate antiproliferative activities in HUVECs ${ }^{[20]}$. The purpose of the present study is to examine the effects of QSN-10c on angiogenesis in vitro (VEGF expression, tube formation, and HUVEC migration) and in vivo (zebra embryo model) as well as the possible mechanisms involved [phosphorylation of proteins involved in the AKT signaling pathway and the mitogen-activated protein kinase pathway (MAPK)]. In addition, QSN-10c also demonstrated enhanced cytotoxicity in K562 leukemic cells in our antitumor screening. Consequently, the mechanism for apoptotic induction in K562 cells is also reported here.

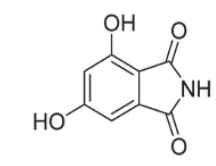

4,6-Dihydroxyisoindol-1,3-dione

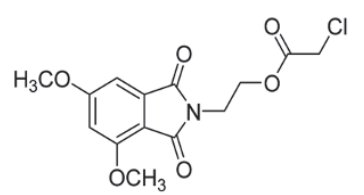

2-(4,6-Dimethoxy-1,3-dioxoisoindolin-2-yl) ethyl 2-chloroacetate

Figure 1. The chemical structures of 4,6-dihydroxyisoindol-1,3-dione, thalidomide and QSN-10c.

\section{Materials and methods Reagents}

QSN-10c was prepared by the Key Laboratory of the Ministry of Education of Shenyang Pharmaceutical University with greater than $98 \%$ purity. Thalidomide was a gift from the Changzhou Pharmaceutical Co, Ltd (China). Antibodies for anti-phospho-AKT $\left(\mathrm{Thr}^{308}\right)$ and anti-AKT were from Bioworld Technology Inc (Minneapolis, USA). Antibodies for antiphospho-GSK3 $\beta$ (Ser $\left.{ }^{9}\right)$, phospho-p44/42 MAPK (ERK1/2) (Thr202/Tyr204), phospho-SAPK/JNK (Thr183/Tyr185), antiGSK3 $\beta$, anti-p44/42 MAPK (ERK1/2) (Thr202/Tyr204), and anti-SAPK/JNK were from Cell Signaling Technology Inc (USA). Antibodies for cytochrome $c$ (A-8), Bcl-2 (C21), Bax (P-19), VEGF (147), and anti-mouse $\beta$-actin (C4) were from Santa Cruz Biotechnology (Santa Cruz, CA, USA). The secondary antibodies were purchased from ZSGB-BIO (Beijing, China). The enhanced chemiluminescent (ECL) plus reagent kit was obtained from the Beyotime Institute of Biotechnology (Haimen, China).

\section{Cell proliferation assay}

HUVEC and K562 cells dispersed evenly in medium (containing $10 \%$ FBS) were seeded and incubated in a 96-well plate at a density of $5 \times 10^{3}$ cells/well for 24 and $1 \mathrm{~h}$, respectively. The cells were then treated with various concentrations of QSN10c, thalidomide, and 4,6-dihydroxyisoindol-1,3-dione for $24 \mathrm{~h}$ with three replicates for each treatment. Methylthiazolyldiphenyl-tetrazolium bromide (MTT) was added to each well for $4 \mathrm{~h}$. After discarding the supernatant, the insoluble formazane product was dissolved in $150 \mathrm{~mL}$ DMSO. The optical density was measured at $490 \mathrm{~nm}$ using an Elx800 microplate reader (Bio-Tek, USA). The percentage of viable cells was calculated using the following equation: $A_{\mathrm{S}} / A_{\mathrm{C}} \times 100 \%$, where $A_{\mathrm{C}}$ is the absorbance of the negative control and $A_{\mathrm{S}}$ is the sample absorbance.

K562 cells were seeded in 6-well plates at a density of $3 \times 10^{5}$ cells per well for $1 \mathrm{~h}$ and then treated with DMSO (0.1\%) and $100 \mu \mathrm{mol} / \mathrm{L}$ QSN-10c for 6, 12, 24, and $48 \mathrm{~h}$. To count the cells, the viable cells were distinguished using trypan blue dye. The number of viable cells was counted. The percentage of viable cells was calculated using the following equation: viable cells (sample)/viable cells (control) $\times 100 \%$. The assay was independently repeated thrice.

\section{Apoptosis detection by flow cytometry}

The sub-diploid (sub- $\mathrm{G}_{1}$ ) population was analyzed by flow cytometry using propidium iodide (PI, sigma) staining as previously described $^{[21]}$. Briefly, HUVEC and K562 cells were treated with $100 \mathrm{\mu mol} / \mathrm{L}$ QSN-10c for 0, 6, 12, 24, and $48 \mathrm{~h}$. The cells were centrifuged at 1500 rounds per minute for 10 min at $4{ }^{\circ} \mathrm{C}$, resuspended in PBS, fixed via the drop-wise addition of ice-cold ethanol (100\%) to a final concentration of $70 \%$ and incubated for $30 \mathrm{~min}$ on ice. The fixed cells were pelleted and treated with $500 \mu \mathrm{L}$ propidium iodide working solution $(100 \mu \mathrm{g} / \mathrm{mL}$ RNase A and $100 \mu \mathrm{g} / \mathrm{mL}$ propidium iodide in PBS) for $30 \mathrm{~min}$ at room temperature protected from light. DNA content was assessed using a FACScan flow cytometer (Becton Dickinson, Heidelberg, Germany). Annexin V staining was also used to detect apoptotic cells according to the FITC Annexin V Apoptosis Detection Kit (Becton, Dickinson 
Company) instructions. The samples were analyzed by flow cytometry.

\section{Measurement of mitochondrial transmembrane potential in flow cytometry}

Mitochondrial membrane potential $(\Delta \psi \mathrm{m})$ was measured using Rhodamine 123 (Rho 123) staining (Sigma). Briefly, treated cells were collected and washed twice with cold PBS. Finally, cells were stained with Rho123 (10 $\mu \mathrm{g} / \mathrm{mL})$ for $30 \mathrm{~min}$ and measured using a FACScan flow cytometer.

\section{Endothelial cell capillary-like tube formation assay}

Matrigel $^{\mathrm{TM}}$ Basement Membrane Matrix (growth factor reduced; BD Biosciences, San Jose, CA, USA) was thawed at $4^{\circ} \mathrm{C}$, pipetted into prechilled 96 -well plates $(50 \mu \mathrm{L}$ Matrigel/ well), and incubated at $37^{\circ} \mathrm{C}$ for $30 \mathrm{~min}$. A total of $1.6 \times 10^{4}$ HUVECs dispersed evenly in medium containing $1 \%$ FBS were placed onto the Matrigel layer in each well. The cells were treated with DMSO $(0.1 \%)$ or various concentrations of QSN-10c $(25,50,100$, and $200 \mu \mathrm{mol} / \mathrm{L})$. After $8 \mathrm{~h}$ of incubation, the network-like structures of endothelial cells were examined using an inverted microscope (Olympus, Tokyo) at $100 \times$ magnification. The tube-like structures were defined as endothelial cord formations connected at both ends ${ }^{[22]}$. The average number of branching points in five random fields per well was quantified using Image Pro-Plus 6.0 software. Cells treated with DMSO $(0.1 \%)$ only served as the vehicle control. The inhibition percentage was expressed as the percentage of the vehicle control $(100 \%)$. The assay was independently repeated thrice.

\section{HUVEC migration in a wound-healing assay}

An in vitro wound-healing assay was performed to measure the unidirectional migration of HUVECs. HUVECs were seeded at $5 \times 10^{5}$ cells per well into a 6-well plate and allowed to grow to full confluence. After starvation with 1640 medium containing $1 \%$ FBS for $12 \mathrm{~h}$ to inactivate cell proliferation, the cells were wounded with a pipette tip, and washed with PBS. Fresh medium was added to the wells with or without DMSO $(0.1 \%)$ or various concentrations of QSN-10c $(50,100$, and $200 \mu \mathrm{mol} / \mathrm{L})$ or thalidomide (100, $200 \mu \mathrm{mol} / \mathrm{L})$, and the cells were incubated for $12 \mathrm{~h}$. Images were obtained at the time of the wounding and at 12-h intervals thereafter using a phasecontrast microscope (Olympus, Tokyo; 100×magnification). Cell migration was quantified according to methods reported in the literature ${ }^{[23]}$. The lesion area in each field of view was measured using the data from time 0 ( $T_{0}$ wound area), and the wound area was then converted to the mean $\%$ recovery $(\% R)$ using the following equation:

$\% R=\left[1-\left(\right.\right.$ wound area at $T_{\mathrm{t}} /$ wound area at $\left.\left.T_{0}\right)\right] \times 100$

where $T_{0}$ is the wounded area $0 \mathrm{~h}$ and $T_{\mathrm{t}}$ is the wounded area $12 \mathrm{~h}$ post-injury. All experiments were performed in triplicate, and each experiment was repeated at least thrice.

The detection of VEGF mRNA levels using RT-PCR

VEGF mRNA levels were detected as previously reported ${ }^{[24]}$.
HUVECs in logarithmic growth phase were seeded into $25-\mathrm{mL}$ culture bottles at a density of $2 \times 10^{5} / \mathrm{mL}$. The cells were divided into control and experimental groups containing 50, 100, and $200 \mu \mathrm{mol} / \mathrm{L}$ QSN-10c. Total cellular RNA was isolated by TRIzol reagent extraction (TaKaRa Biotech, China) at the indicated times. Total RNA $(5 \mu \mathrm{g})$ was reverse transcribed into cDNA using the TIANScript RT reagent kit (Tiangen Biotech Co, Ltd, Beijing). The following primers were designed and synthesized by Takara Bio: VEGF-A sense, 5' TGC TGC TCT TCC TC-3' and VEGF-A antisense, 5'-TGC ATG GTG ATG TTG GAC TC-3' (280 bp product); GAPDH sense, 5'-GCA CCG TCA AGG CTG AGA AC-3' and GAPDH antisense, 5'-ATG GTG GTG AAG ACG CCA GT-3' (142 bp product). The following reaction conditions were used: $95^{\circ} \mathrm{C}$ for $5 \mathrm{~min}$; 30 cycles of $94^{\circ} \mathrm{C}$ for $30 \mathrm{~s}, 63^{\circ} \mathrm{C}$ for $30 \mathrm{~s}$, and $72^{\circ} \mathrm{C}$ for $30 \mathrm{~s}$; extension at $72^{\circ} \mathrm{C}$ for $7 \mathrm{~min}$. For the PCR product analysis, VEGF and GAPDH PCR products from the same sample were observed using $2 \%$ agarose gel electrophoresis. The images were obtained using a gel imaging system, and the target gene expression levels were measured via semiquantitative analysis.

The relative mRNA content=accumulative photon value of the target gene band/accumulative photon value of the internal standard GAPDH band.

\section{Western blotting}

Adherent cells were washed thrice with ice-cold phosphate buffered saline (PBS) before lysed in RIPA buffer containing the following protease and phosphatase inhibitors: aprotinin (10 mg/mL), leupeptin (10 mg/mL), phenylmethylsulfonyl fluoride (1.72 mmol/L), $\mathrm{NaF}(100 \mathrm{mmol} / \mathrm{L})$, and $\mathrm{NaVO}_{3}$ (500 mmol/L). K562 cells were collected and then lysed as described above. Equal amounts of protein were separated by $12 \%$ sodium dodecyl sulfate-polyacrylamide gel electrophoresis and transferred onto PVDF membranes. The blots were incubated with primary antibodies followed by secondary antibody conjugated to horseradish peroxidase; antibody binding was detected with BeyoECL Plus.

\section{Anti-angiogenic activity in the zebrafish embryo model}

The in vivo anti-angiogenic activity of QSN-10c was further investigated in the zebrafish embryo according to standard operation practices ${ }^{[25]}$. Briefly, zebrafish embryos were generated by natural pair-wise mating and raised at $28.5^{\circ} \mathrm{C}$ in embryo water $(5 \mathrm{mmol} / \mathrm{L} \mathrm{NaCl}, 0.17 \mathrm{mmol} / \mathrm{L} \mathrm{KCl}, 0.4$ $\mathrm{mmol} / \mathrm{L} \mathrm{CaCl}_{2}, 0.16 \mathrm{mmol} / \mathrm{L} \mathrm{MgSO}_{4}$ ). QSN-10c was diluted in DMSO as needed and then transferred to the embryo water. Healthy, hatched zebrafish embryos were selected at $24 \mathrm{hpf}$ (hours post fertilization), and treated with DMSO $(0.1 \%)$ or varying concentrations of QSN-10c $(5,10$, and $20 \mu \mathrm{g} / \mathrm{mL})$. The embryos were then incubated in 24-well plates (10-15 embryos/well) at $28.5^{\circ} \mathrm{C}$ from 24 to $48 \mathrm{hpf}$. At $48 \mathrm{hpf}$, the zebrafish were removed from the 24 -well plates, and viability and vessel morphological changes were assessed. The zebrafish section just below the yolk sac was selected for the assessment of complete intersegmental vessels (ISVs) by manual 
counting. ISVs with blood flow were counted as effective; therefore, images could not be obtained. Embryos treated with DMSO $(0.1 \%)$ served as the vehicle control. The assay was independently repeated thrice. The percentage of inhibition ratio $=\left[1-\left(\mathrm{ISVs}_{(\text {(sample) }} / \mathrm{ISVs}_{(\text {(control) }}\right)\right] \times 100 \%$.

\section{Statistical analysis}

The results were expressed as the mean \pm SD. Statistical significance was compared between the QSN-10c-treated and control groups using Student's $t$-test. Results with $P<0.05$ were considered significantly different from the control. The significance of the difference between two groups was assessed using Student's $t$-test.

\section{Results}

QSN-10c decreases the viability of HUVEC and K562 cells

To elucidate the anti-angiogenic effects of QSN-10c in vitro, the viability of human umbilical vein endothelial cell (HUVEC) treated with QSN-10c for $24 \mathrm{~h}$ was evaluated. In addition, the effect of QSN-10c on K562 cell viability was also examined. Similar to our previous studies, QSN-10c induced minimal reduction in the growth rate of HUVEC cells with an $\mathrm{IC}_{50}$ value greater than $150 \mu \mathrm{mol} / \mathrm{L}$ (Figure 2A). QSN-10c inhibited $\mathrm{K} 562$ cell viability with an $\mathrm{IC}_{50}$ value of $114.0 \pm 2.3 \mu \mathrm{mol} / \mathrm{L}$; this effect is greater than that observed for thalidomide and 4,6-dihydroxyisoindol-1,3-dione (Figure 2B). The decrease in cell viability upon treatment with $100 \mu \mathrm{mol} / \mathrm{L}$ QSN-10c was time-dependent in K562 cells (Figure 2C).

QSN-10c induces apoptosis in a time- and concentration-dependent manner in K562 cells

The sub-diploid (sub- $\mathrm{G}_{1}$ ) population after PI staining was quantified to determine the extent of apoptosis induced by QSN-10c. A time-dependent increase in sub- $\mathrm{G}_{1}$ cells was visible after treatment with $100 \mu \mathrm{mol} / \mathrm{L}$ QSN-10c (Figure 3A, 3B, $6,12,24$, and $48 \mathrm{~h}$ after treatment resulted in $3.47 \% \pm 0.11 \%$, $4.31 \% \pm 0.46 \%, 5.38 \% \pm 0.51 \%, 11.27 \% \pm 0.73 \%$ sub $-G_{1}$ cells, respectively, vs $1.75 \% \pm 0.17 \%, 2.10 \% \pm 0.28 \%, 2.16 \% \pm 0.29 \%$, $2.25 \% \pm 0.21 \%$ in the respective control groups). However, no significant apoptotic induction was observed in HUVEC cells treated with the same QSN-10c concentration (data not shown).

To further characterize QSN-10c-induced apoptosis in K562 cells, annexin $\mathrm{V}$ staining was performed. The results demonstrate an approximate 3- to 11-fold increase in the apoptotic fraction of the groups treated with $50-150 \mu \mathrm{mol} / \mathrm{L}$ QSN-10c compared with the control (Figure 3C, 3D). Whereas, 100-200 $\mu \mathrm{mol} / \mathrm{L}$ QSN-10c displayed minimal induction of apoptosis in HUVEC cells (Figure 3E).

QSN-10c-induced apoptosis is accompanied by mitochondrial changes and mitochondria-related protein alterations

Many anti-neoplastic drugs induce apoptosis in cancer cells via the mitochondrial apoptotic pathway ${ }^{[26-29]}$. A hallmark of death induction via this pathway is a rapid and early loss of the mitochondrial membrane potential $(\Delta \psi \mathrm{m})$. Thus, we ana-
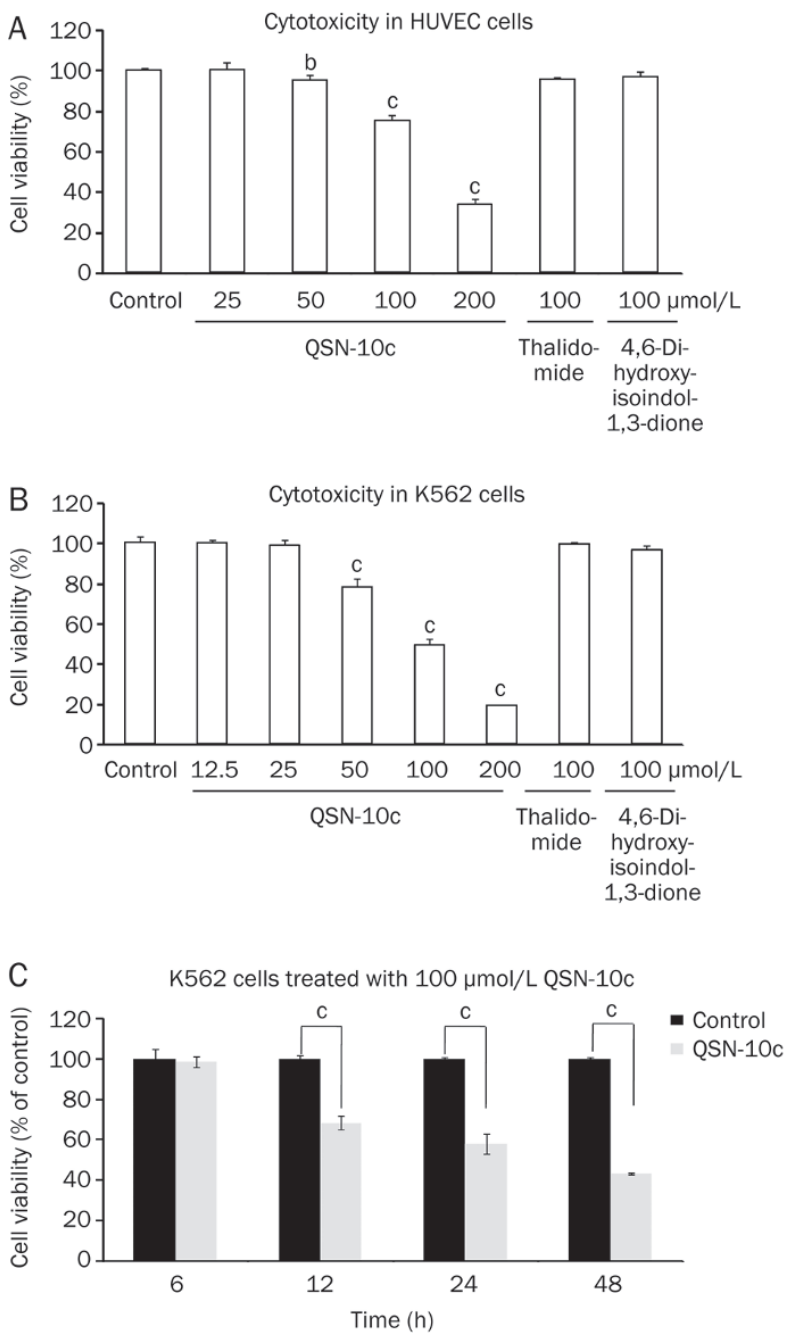

Figure 2. Effects of QSN-10c on viability of HUVECs and K562 cells. (A) Antiproliferative activity in HUVECs after $24 \mathrm{~h}$ exposure. (B) Cytotoxicity in K562 cells after $24 \mathrm{~h}$ exposure. QSN-10c inhibited the viability of K562 cells in a dose-dependent manner. (C) K562 cells were cultured in 6-well plates for different time periods in the presence of $100 \mu \mathrm{mol} / \mathrm{L}$ QSN10c. The viability was decreased in a time-dependent manner. Data were expressed as mean \pm SD. $n=3 .{ }^{b} P<0.05,{ }^{c} P<0.01$ compared with control. Thalidomide was given as positive control.

lyzed the integrity of mitochondrial function after treatment with QSN-10c. QSN-10c treatment resulted in a significant concentration-dependent breakdown of the $\Delta \psi \mathrm{m}$ (Figure $4 \mathrm{~A}$, $48 \mathrm{~h}$ after treatment with 50,100, or $150 \mu \mathrm{mol} / \mathrm{L}$ QSN-10c). HUVEC cells treated with QSN-10c showed no change in $\Delta \psi \mathrm{m}$ (Figure 4B).

Given that changes in the mitochondrial membrane potential are typically associated with increased permeability of the outer mitochondrial membrane that promotes efflux of apoptogenic proteins to the cytosol ${ }^{[30]}$, we measured the release of cytochrome $c$ from the mitochondria to the cytosol by Western blot. As expected, the expression of cytoplasmic cytochrome $c$ increased in a dose-dependent manner (Figure 4C). Changes in mitochondrial membrane potential can result from the 
A
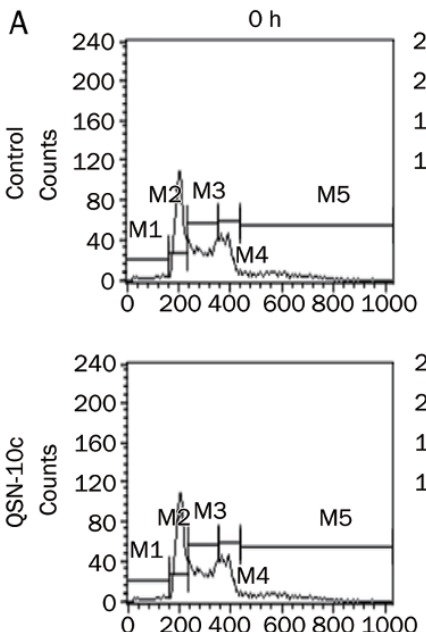

B

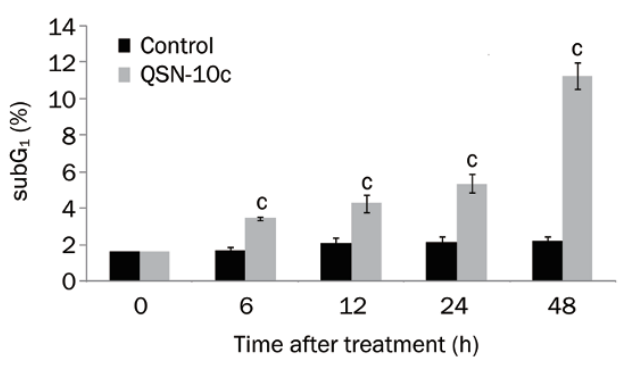

D

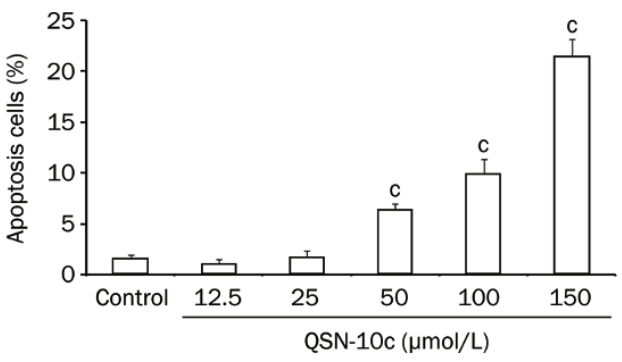

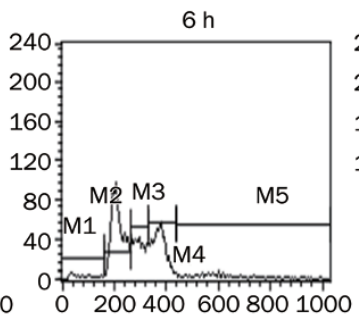
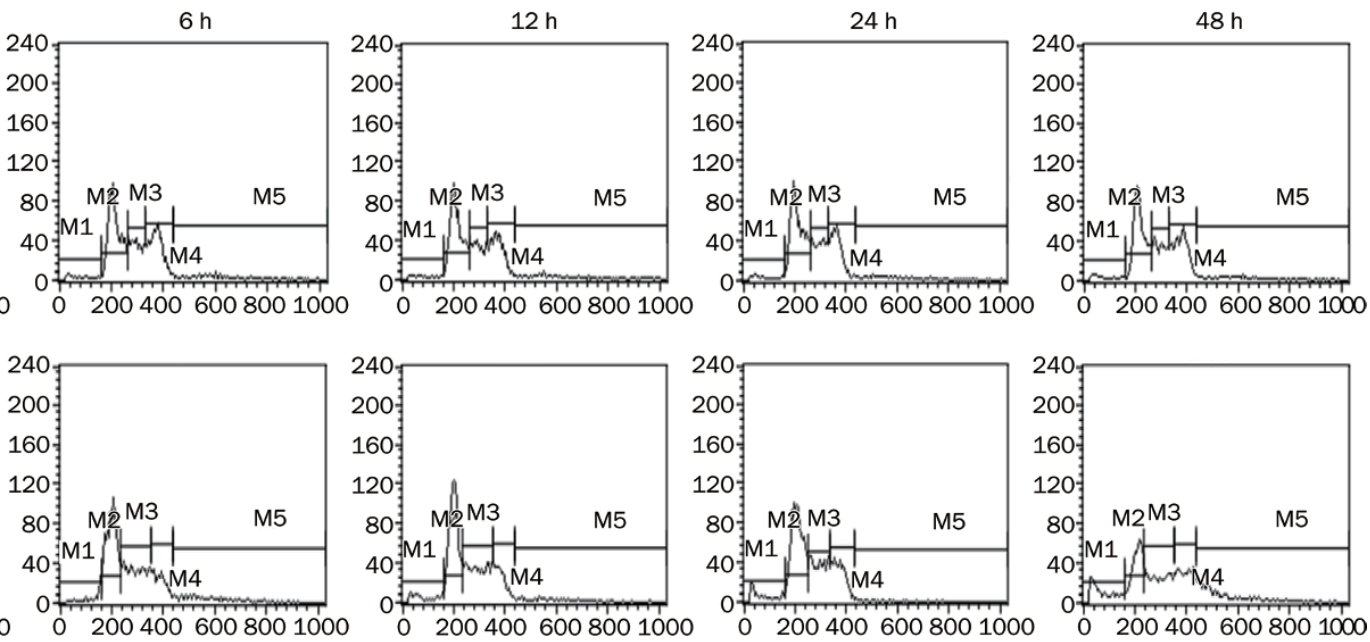

FL2-A
C
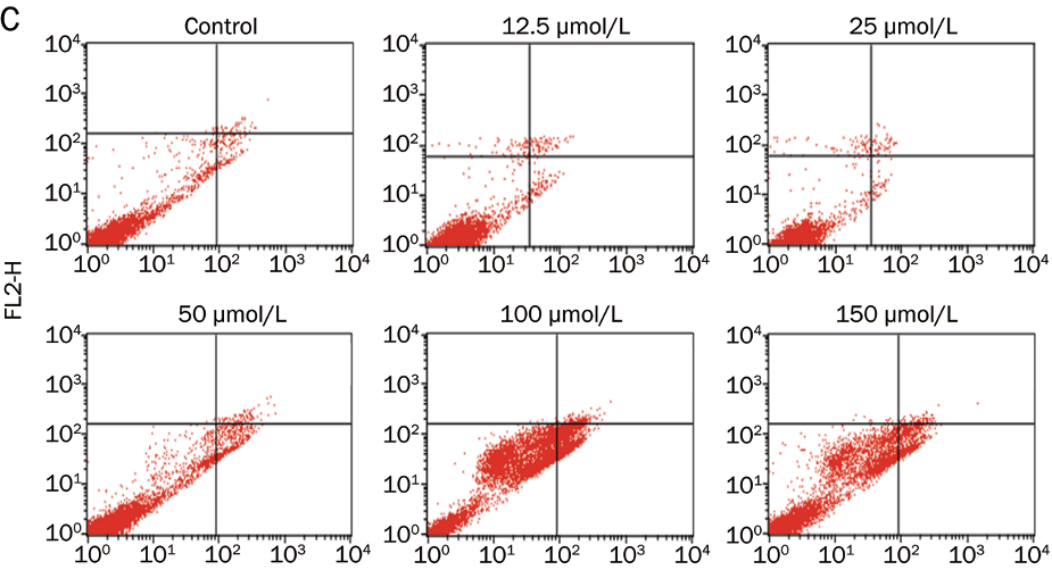
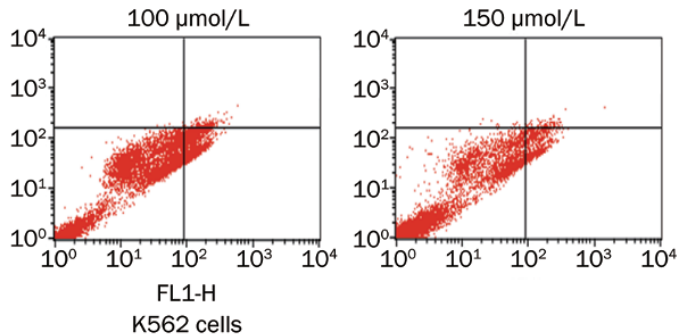

$\mathrm{E}$
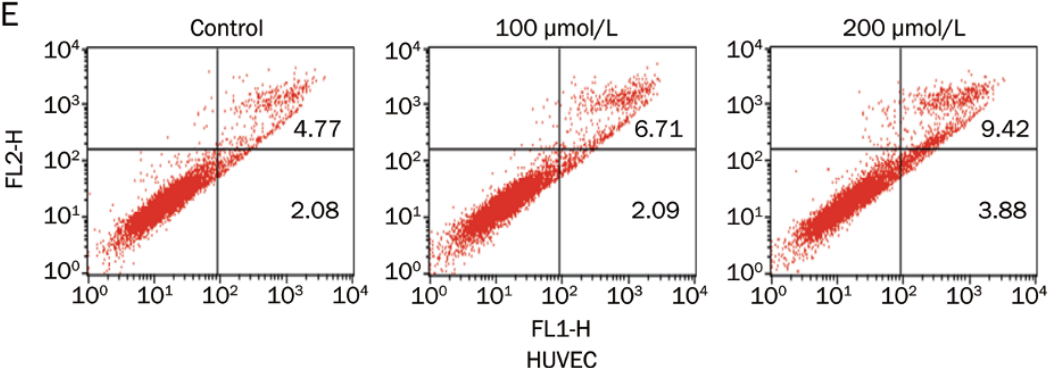

Figure 3. QSN-10c increased apoptosis in K562 cells and HUVECs. PI staining (A-B) and FITC-conjugated Annexin V/PI staining (C-D) were conducted to evaluate the cell apoptosis induced by QSN-10c. (A) Representative patterns of flowcytometric distribution of K562 cells treated with QSN-10c for different time. $M 1$ marks subG ${ }_{1}$ apoptosic cells. (B) Quantitative comparison of the numbers of subG $\mathrm{G}_{1}$ phase in different groups. (C) Representative patterns of flowcytometric distribution of K562 cells. Dot plot was divided into a quadrant: upper left, necrotic cells; upper right, late apoptotic cells; lower left, living cells; and lower right, early apoptotic cells. (D) Graphs demonstrate the sum of cells in early and late apoptosis of K562 cells. (E) Representative patterns of flowcytometric distribution of HUVEC. Cells receiving only DMSO $(0.1 \%)$ served as a vehicle control. Data were expressed as mean \pm SD. $n=3 .{ }^{c} P<0.01$ vs control.

action of pro- and/or anti-apoptotic members of the Bcl-2 family $^{[31]}$. Thus, we examined the effects of QSN-10c on Bcl-2 and Bax protein expression. The Western blot revealed that QSN$10 \mathrm{c}$ reduces the expression of the anti-apoptotic protein $\mathrm{Bcl}-2$ and increases the levels of the pro-apoptotic protein Bax in a dose-dependent manner (Figure 4C).

\section{The effects of QSN-10c on tube formation in HUVECs}

Although angiogenesis is a complex procedure involving various cell types, endothelial cell tube formation is a key step of angiogenesis $^{[32]}$. To further assess the effects of QSN-10c on endothelial cell tube formation, we used a two-dimensional Matrigel assay to examine the effect of QSN-10c on HUVEC 
A
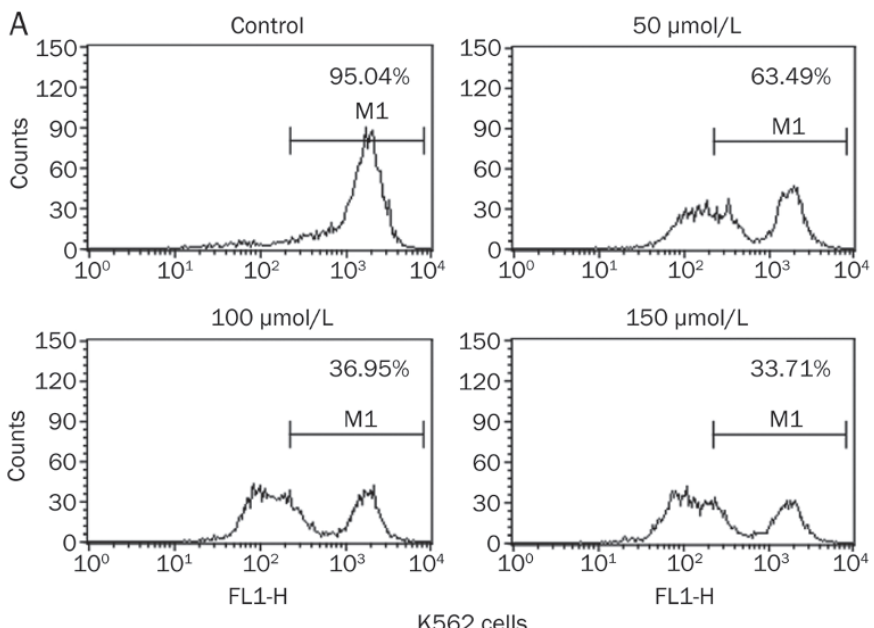

B
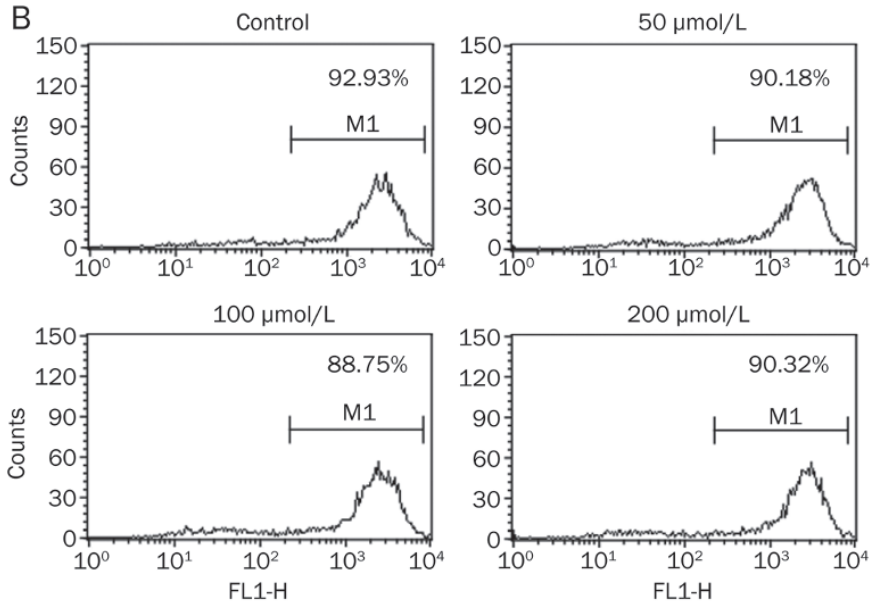

HUVEC

C

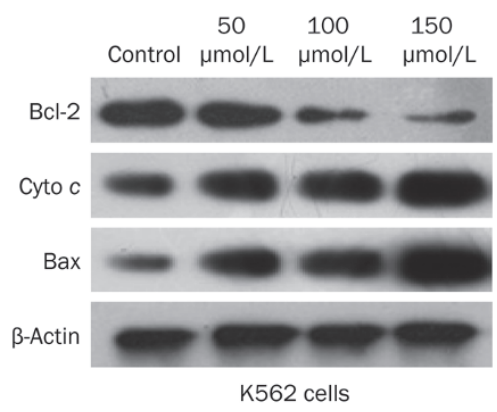

Figure 4. Effects of QSN-10c on mitochondrial membrane potential and expression of mitochondria-related apoptotic proteins. (A-B) The mitochondrial membrane potential of $\mathrm{K} 562$ cells treated with QSN-10c was decreased in a dose-dependent manner. (C) Treatment of cells with various concentrations of $\mathrm{QSN}-10 \mathrm{c}$ for $48 \mathrm{~h}$ resulted in dose-dependent increase in the release of cytochrome $c$, and in the expression of Bax. The level of $\mathrm{Bcl}-2$ was decreased in a dose-dependent manner.

tube formation. When HUVECs were seeded on the Matrigel, robust tubular-like structures were formed. Capillary tube formation on Matrigel was inhibited by approximately $7.4 \%$ after treatment with $25 \mu \mathrm{mol} / \mathrm{L}$ QSN-10c for $8 \mathrm{~h}(P>0.05)$. Tube formation was inhibited by approximately $50 \%$ with $50 \mu \mathrm{mol} / \mathrm{L}$
QSN-10c, and tube formation was almost completely inhibited upon treatment with $200 \mu \mathrm{mol} / \mathrm{L}$. The QSN-10c-mediated effects were more robust than the results of treatment with 4,6-dihydroxyisoindol-1,3-dione and thalidomide (Figure 5A-5G, $P<0.05, P<0.01)$.

\section{The effects of QSN-10c on HUVEC migration}

As cell migration is also essential for angiogenesis in endothelial cells ${ }^{[33]}$, we investigated the inhibitory effects of QSN-10c on the chemotactic motility of endothelial cells using a woundhealing migration assay. We discovered that QSN-10c inhibits HUVEC migration in a dose-dependent manner, with significant inhibition at 100-200 $\mathrm{mmol} / \mathrm{L}$ (Figure 6A-6G, $P<0.01$, $P<0.001)$. These findings indicate that QSN-10c may inhibit angiogenesis in vitro by preventing endothelial cell migration and tubular structure formation.

\section{VEGF levels are decreased in HUVEC cells}

To investigate whether QSN-10c modulates the VEGFmediated autocrine effects on endothelial cells, RT-PCR and Western blot were performed to examine VEGF expression in HUVECs. The results indicated that $24 \mathrm{~h}$ of treatment with 50-100 $\mu \mathrm{mol} / \mathrm{L}$ QSN-10c clearly decreased VEGF mRNA levels (Figure $7 \mathrm{~A}, 7 \mathrm{~B}, P<0.05$ ). We further determined the effect of QSN-10c on VEGF expression by Western blot. QSN-10c decreased VEGF protein in a dose-dependent manner compared with the control (Figure 7C). These results suggest that QSN-10c-mediated VEGF inhibition potentially contributes to reduced angiogenesis by HUVECs.

The PI3K/AKT/GSK3ß pathway is involved in QSN-10c-mediated. antiangiogenesis and $K 562$ cell apoptosis

To investigate the molecular mechanism of QSN-10c-mediated antiangiogenesis, we examined the effect of QSN-10c on the activity of AKT and GSK3 $\beta$, important components of the PI3K/AKT signaling pathway that plays a crucial role in HUVEC migration ${ }^{[34]}$. Our data indicated that AKT and GSK3 $\beta$ phosphorylation were significantly reduced by QSN10c in a dose-dependent manner in HUVEC cells. However, QSN-10c did not affect the phosphorylation of ERK1/2 and JNK, signal proteins involved in the MAPK pathway (Figure 8A). To investigate the role of the PI3K/AKT signaling pathway in QSN-10c-mediated apoptosis in K562 cells, we also examined the expression of AKT and GSK3 $\beta$ in K562 cells treated with various concentrations of QSN-10c. The result suggest that QSN-10c also inhibits the expression of p-AKT and p-GSK3 $\beta$ in a dose-dependent manner (Figure 8B), indicating that QSN-10c induces K562 cell apoptosis at least in part via inhibition of the PI3K/AKT pathway.

\section{Anti-angiogenic activity in zebrafish embryo model}

Based on QSN-10c activities in vitro, we further evaluated the anti-angiogenic property of QSN-10c in a zebrafish embryo model. Zebrafish embryos were treated with DMSO (0.1\%) or various concentrations of QSN-10c $(5,10$, and $20 \mu \mathrm{g} / \mathrm{mL})$ from the shield stage ( $24 \mathrm{hpf}$ ) to $48 \mathrm{hpf}$. Significant reductions 

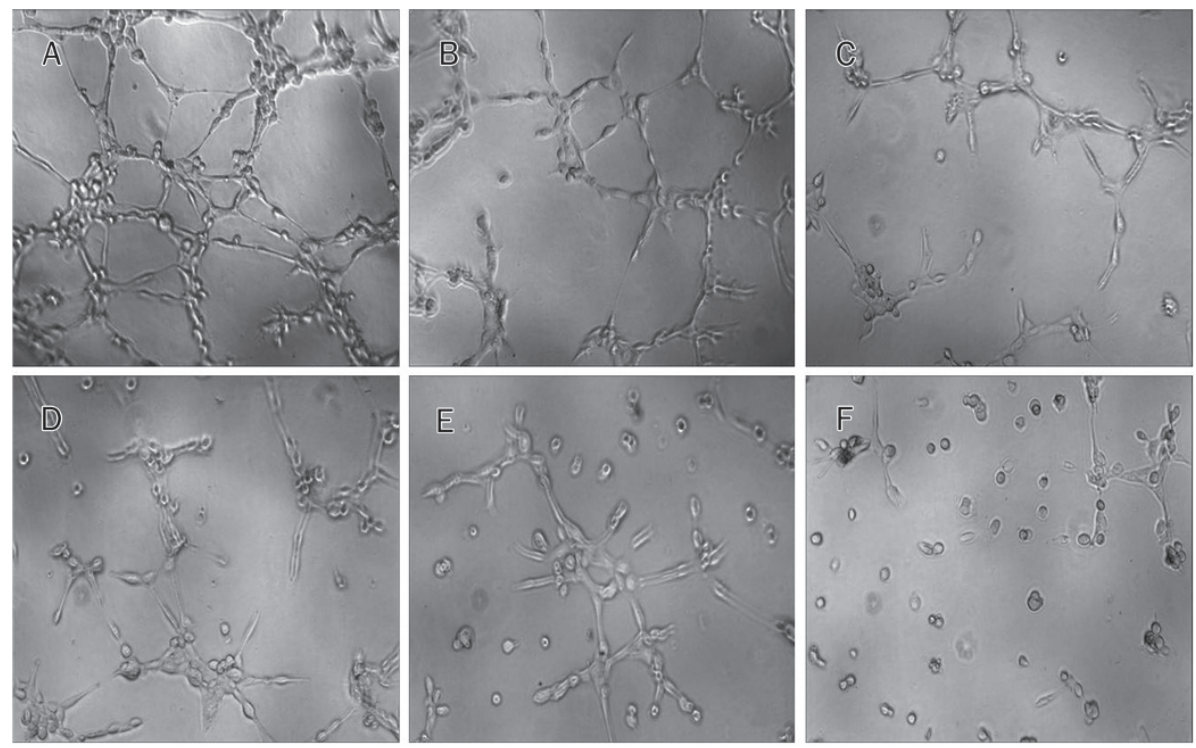

G

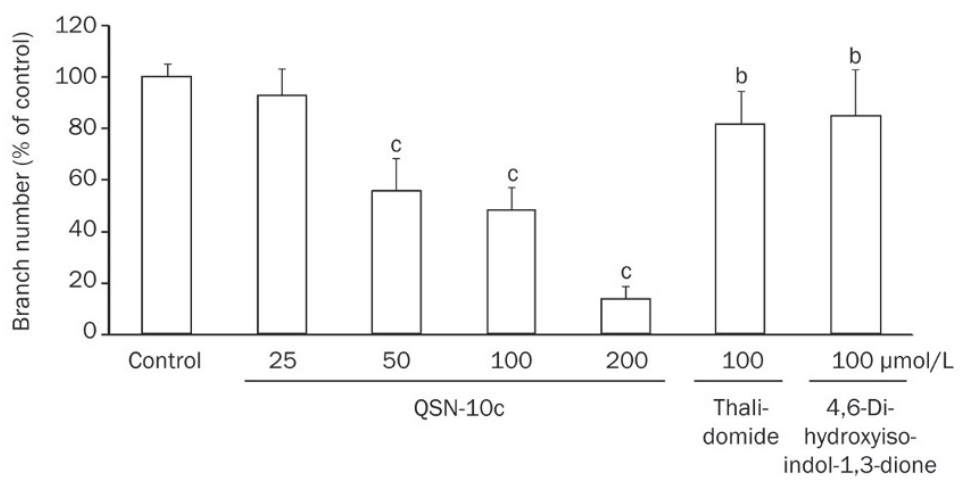

Figure 5. QSN-10c inhibits capillary structure formation of endothelial cells on Matrigel. (A) HUVECs cultured on Matrigel were treated with only DMSO (0.1\%). (B, C) HUVECs cultured on Matrigel were treated with $100 \mu \mathrm{mol} / \mathrm{L}$ of thalidomide and 4,6-dihydroxyisoindol-1,3-dione, respectively. (DF) HUVECs cultured on Matrigel were treated with various concentrations of QSN-10c (50, 100, and $200 \mu \mathrm{mol} / \mathrm{L})$. (G) Quantitative comparison of the numbers of branching points in different groups. Cells receiving only DMSO (0.1\%) served as a vehicle control, thalidomide as a positive control. Data are expressed as percentages of the vehicle control (100\%) in mean \pm SD from three independent experiments. ${ }^{b} P<0.05,{ }^{c} P<0.01$ compared with control.

in the number of complete ISVs were observed in the 10-20 $\mu \mathrm{g} / \mathrm{mL}$ QSN-10c-treated groups compared with the vehicle control group (Figure 9, $P<0.05$ ).

\section{Discussion}

Angiogenesis is now recognized as playing a crucial role in the initiation and progression of many diseases, such as cancer and RA, and anti-angiogenic interventions are becoming a promising approach for the treatment of these diseases. Many reported agents possess anti-angiogenic activity via the inhibition of HUVEC proliferation, migration, and tube formation in vitro. Moreover, bevacizumab (Avastin, anti-VEGF monoclonal antibody) and vatalanib (VEGFR inhibitor) are approved for the treatment of various malignant tumors by targeting angiogenic pathways. Thalidomide [a-(N-phthalimido)-glutarimide] is an immunomodulatory and anti-angiogenic drug. Recent research has shown that the drug has antitumoral properties, and promising results from thalidomide treatment in patients with myeloma, myelodysplastic syndrome, and variety of solid tumors has been reported ${ }^{[35]}$. However, thalidomide has been shown to require bio-activation to exert its anti-angiogenic effect in isolated blood vessels and endothelial cells ${ }^{[36,37]}$. Moreover, thalidomide displayed varying antiangiogenic activities in endothelial cells (ECs) in the literature $^{[38,39]}$. Thus, the specific mechanism of antitumoral action for thalidomide remains unclear. In this study, thalidomide was used as positive control and displayed minimal antiangiogenic activities, similar to previous findings $\mathrm{s}^{[39]}$.

The preliminary comparison between 4,6-dihydroxyisoindol-1,3-dione and thalidomide has been previously performed. Because 4,6-dihydroxyisoindol-1,3-dione exhibits specific antiangiogenic activities, a series of derivatives were subsequently synthesized, and then their cytotoxicity and anti-angiogenic activity was evaluated in tumor cells to identify candidates with enhanced properties. Among the derivatives, QSN10c displayed moderate cytotoxicity in A549 and HUVEC 

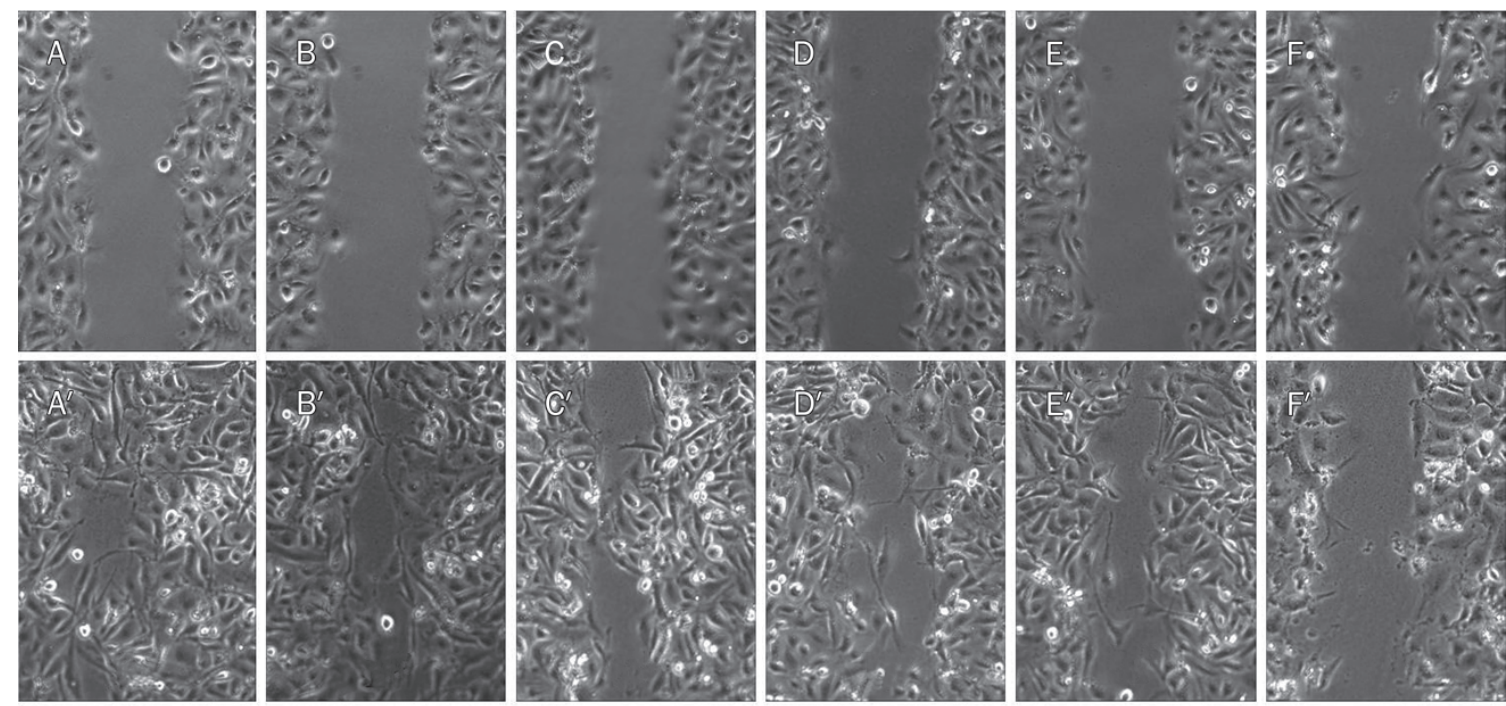

G

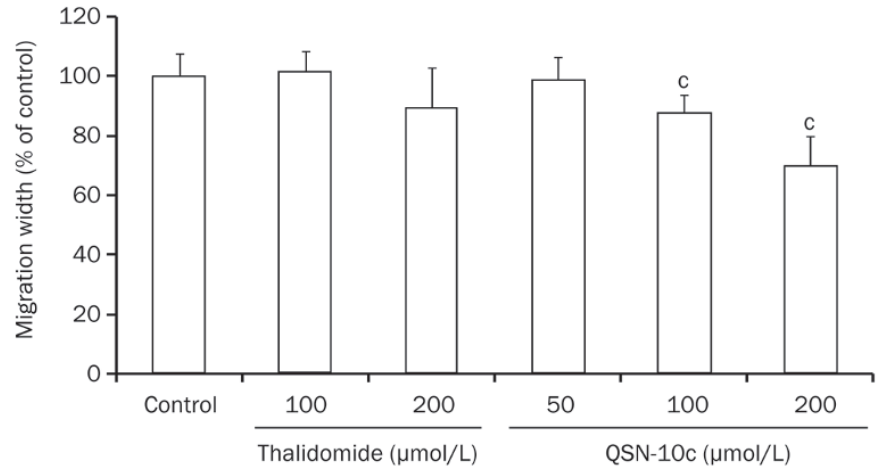

Figure 6. QSN-10c inhibits chemotactic motility of endothelial cells. (A/A') Migration assay of HUVECs treated with only DMSO $(0.1 \%)(0 \mathrm{~h} / 12 \mathrm{~h})$. (B, $\left.\mathrm{C} / \mathrm{B}^{\prime}, \mathrm{C}^{\prime}\right)$ Migration assay of HUVECs treated with different concentrations (100-200 $\left.\mu \mathrm{mol} / \mathrm{L}\right)$ of thalidomide $(0 \mathrm{~h} / 12 \mathrm{~h})$. (D-F/D'-F') Migration assay of HUVECs treated with different concentrations (50-200 $\mu \mathrm{mol} / \mathrm{L})$ of QSN-10c $(0 \mathrm{~h} / 12 \mathrm{~h})$. (G) Quantitative comparison of the average migrated width in different groups. Cells receiving only DMSO (0.1\%) served as a vehicle control, receiving thalidomide as positive control. Data are expressed as percentages of the vehicle control $(100 \%)$ in mean \pm SD from three independent experiments. ${ }^{\circ} P<0.01$ compared with control.

cells in our previous study. To further elucidate the effects of QSN-10c on angiogenesis and hematologic neoplasms, we employed in vitro HUVEC models (migration, tube formation, and VEGF expression) and an in vivo zebrafish embryo model. In addition, the cytotoxicity of QSN-10c was investigated in K562 cells. Under the conditions used in this study, QSN-10c exhibited better antiproliferative activity than thalidomide and 4,6-dihydroxyisoindol-1,3-dione in K562 cells. Additional studies suggested that $100 \mu \mathrm{mol} / \mathrm{L}$ QSN-10c induces apoptosis via the mitochondrial apoptotic pathway. In endothelial cells, 50-200 $\mu \mathrm{mol} / \mathrm{L}$ QSN-10c also exhibited enhanced inhibition of HUVEC migration and tube formation as well as VEGF expression. Furthermore, we showed that QSN-10c inhibits angiogenesis in an in vivo zebrafish model.

With regard to molecular targeting mechanisms, VEGFmediated biological effects initiate the binding of VEGF to VEGFR-2, thereby resulting in the autophosphorylation of tyrosine residues in the receptors. In fact, the Tg (VEGFR2: GFP) transgenic zebrafish model that expresses fluorescent tags in endothelial cells was first employed to evaluate the anti-angiogenic activity of QSN-10c. In this transgenic line, QSN-10c showed no inhibitory activity (data not shown), indicating that QSN-10c possibly has no effect on VEGFR2 protein. Consequently, a non-transgenic zebrafish embryo model was used for further studies, and the primary downstream pathways were investigated by Western blot to elucidate in part the anti-angiogenic mechanism of QSN-10c. Our preliminary studies indicate that QSN-10c inhibits the activities of AKT (protein kinase B) and GSK3 $\beta$, crucial proteins in the $\mathrm{PI} 3 \mathrm{~K} / \mathrm{AKT}$ signaling pathway. PI3K is activated in response to diverse mitogenic signals and catalyzes the formation of the secondary lipid messenger phosphatidylinositol-3,4,5triphosphate. AKT binds to phosphatidylinositol-3,4,5-triphosphate via pleckstrin homology domains and is recruited to the plasma membrane, where AKT is phosphorylated at $\mathrm{Thr}^{308}$ by phosphoinositide dependent kinase-1 (PDK1) and subsequently activated. Also in K562 cells, the decrease of AKT and GSK3 $\beta$ was found. Interestingly, EC migration is AKT-phosphatidylinositol-3-kinase (PI3K) dependent ${ }^{[40-42]}$, and the PI3K/AKT pathway transduces anti-apoptotic signals 
A

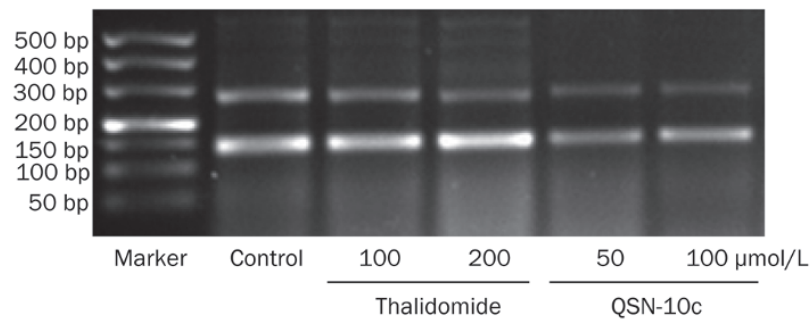

B

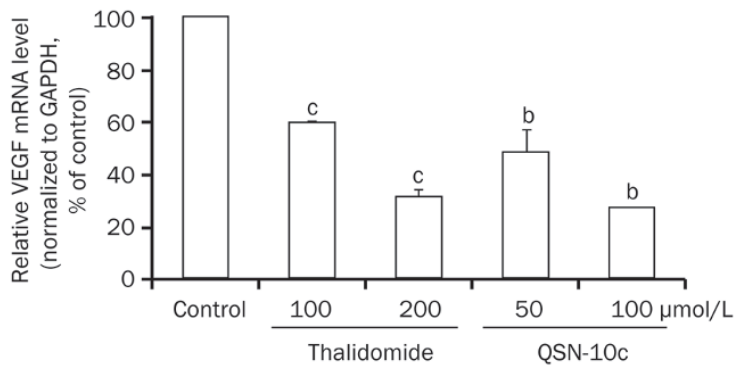

C

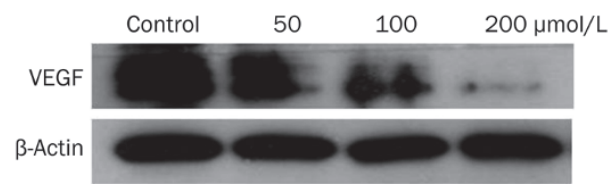

Figure 7. Effects of QSN-10c on VEGF expression in HUVECs. (A) Electrophoresis bands expressed with VEGF and internal standard GAPDH mRNA in various groups treated with different concentrations of thalidomide and QSN-10c. The upper bands were corresponded to VEGF, and the lower to GAPDH. (B) Relative VEGF mRNA levels were quantified by integral optical density analysis of the bands from (A) and then normalization to GAPDH in HUVECs. Cells received thalidomide as positive control. Data are expressed as percentages of the vehicle control (100\%) in mean $\pm S D$ from three independent experiments. ${ }^{b} P<0.05,{ }^{c} P<0.01$ compared with control. (C) HUVECs were treated with QSN-10c for $24 \mathrm{~h}$. Cell extract was prepared and subjected to Western blot using anti-VEGF antibody. $\beta$-Actin served as a loading control. QSN-10c decreased VEGF protein expression in HUVECs in a dose dependent manner as detected by Western blot.

in tumor cells ${ }^{[43,44]}$. AKT inhibition has been reported to follow the induction of the downstream mitochondrial apoptotic pathway by alterations in the Bcl-2/Bax ratio ${ }^{[45,46]}$. According to increasing evidence regarding the importance of angiogenesis in hematologic neoplasms, the antiproliferative and antiangiogenic activity of QSN-10c in hematologic K562 cells may support further systematic studies.

VEGF is a potent pro-angiogenic factor that stimulates endothelial cells. Kim $\mathrm{KH}$ et al found that galbanic acid isolated from Ferula assafoetida could inhibit the proliferation of HUVECs stimulated by VEGF better than HUVECs under non-proliferative conditions (ie, without additional angiogenic growth factors ${ }^{[47]}$. Given the similarity between QSN-10c and thalidomide as well as the unclear molecular mechanisms of QSN-10c, the effect of QSN-10c on HUVEC proliferation, migration, and capillary structure formation was evaluated without VEGF stimulation. Based on the data from our study, 50-200 $\mathrm{\mu mol} / \mathrm{L}$ QSN-10c demonstrated specific anti-angio-

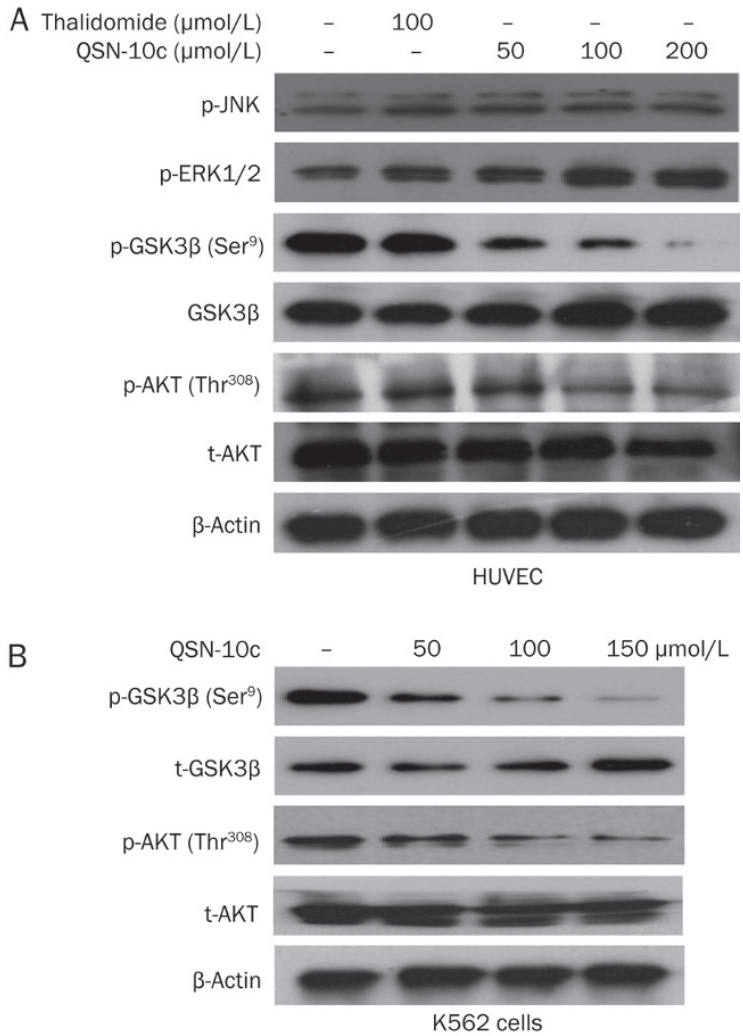

Figure 8. Effects of QSN-10c on phosphorylation of proteins involved in $\mathrm{PISK} / \mathrm{AKT}$ and MAPK signaling pathway. (A) HUVEC cells were treated with desired concentrations of QSN-10c for $24 \mathrm{~h}$, cell lysates subjected to Western blot analysis with phospho-Thr ${ }^{308}$ AKT and total AKT antibodies respectively. Phospho-GSK3 $\beta$, JNK, and ERK1/2 were also analyzed. (B) K562 cells were treated with desired concentrations of QSN-10c for $48 \mathrm{~h}$, cell lysates subjected to western blot analysis with phospho-Thr ${ }^{308} \mathrm{AKT}$, total AKT, phosphor-Ser9 GSK3 $\beta$ and total GSK3 $\beta$ antibodies, respectively. $\beta$-Actin reprobing is showing equal loading of the total protein samples.

genic activities in endothelial cells as well as inhibition of the AKT signaling pathway. We hypothesize that QSN-10c might display enhanced activity under mitogen-activated conditions (ie, VEGF stimulation); however, this hypothesis requires further testing.

In conclusion, our findings indicate that QSN-10c inhibits angiogenesis in vitro, and this effect is mediated by inhibition of endothelial cell tube formation and migration. The inhibition of these endothelial cell activities is mediated in part through inhibition of the AKT pathway, which plays multiple roles in the regulation of neovascularization. Furthermore, QSN-10c also directly induces apoptosis in K562 leukemia cells via the mitochondrial apoptotic pathway. On the basis of these findings, QSN-10c could serve as an effective candidate for further study. In addition, more derivatives with enhanced efficacy can be designed.

\section{Acknowledgements}

The authors are very grateful to Yan-qiang YUAN from the Biology Institute of Shandong Academy of Sciences for pro- 


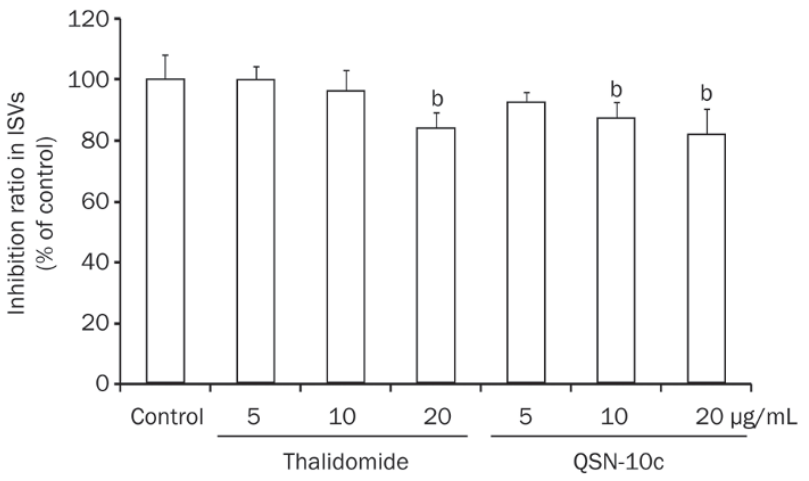

Figure 9. QSN-10c inhibits blood vessel formation in ISVs of zebrafish embryos. Quantitative comparison of blood vessel formation in the vehicle control group and QSN-10c-treated groups. Data are expressed as mean \pm SD from three independent experiments. ${ }^{b} P<0.05$ compared with vehicle control.

viding the zebrafish embryo research platform.

\section{References}

1 Folkman J. Angiogenesis in cancer, vascular, rheumatoid and other disease. Nat Med 1995; 1: 27-31.

2 Carmeliet P, Jain RK. Angiogenesis in cancer and other diseases. Nature 2000; 407: 249-57.

3 Padró T, Ruiz S, Bieker R, Bürger H, Steins M, Kienast J, et al. Increased angiogenesis in the bone marrow of patients with acute myeloid leukemia. Blood 2000; 95: 2637-44.

4 Negaard HF, Iversen N, Bowitz-Lothe IM, Sandset PM, Steinsvik B, Ostenstad B, et al. Increased bone marrow microvascular density in haematological malignancies is associated with differential regulation of angiogenic factors. Leukemia 2009; 23: 162-9.

5 Li WW, Hutnik M, Gehr G. Antiangiogenesis in haematological malignancies. Br J Haematol 2008; 143: 622-31.

6 Tosetti F, Ferrari N, De Flora S, Albini A. Angioprevention: angiogenesis is a common and key target for cancer chemopreventive agents. FASEB J 2002; 16: 2-14.

7 El Sayed KA. Natural products as angiogenesis modulators. Mini Rev Med Chem 2005; 5: 971-93.

8 Papetti M, Herman IM. Mechanisms of normal and tumor-derived angiogenesis. Am J Physiol Cell Physiol 2002; 282: C947-70.

9 Ciccarelli M, Santulli G, Campanile A, Galasso G, Cervero P, Altobelli $\mathrm{GG}$, et al. Endothelial alpha1-adrenoceptors regulate neo-angiogenesis. Br J Pharmacol 2008; 153: 936-46.

10 Hanahan D, Folkman J. Patterns and emerging mechanisms of the angiogenic switch during tumorigenesis. Cell 1996; 86: 353-64.

11 Folkman J. Fundamental concepts of the angiogenic process. Curr Mol Med 2003; 3: 643-51.

12 Ferrara N, Kerbel RS. Angiogenesis as a therapeutic target. Nature 2005; 438: 967-74.

13 Semenza GL. HIF-1: using two hands to flip the angiogenic switch. Cancer Metastasis Rev 2000; 19: 59-65.

14 Millauer B, Wizigmann-Voos S, Schnurch H, Martinez R, Moller NP, Risau W. High affinity VEGF binding and developmental expression suggest Flk-1 as a major regulator of vasculogenesis and angiogenesis. Cell 1993; 72: 835-46.

15 Wu LW, Mayo LD, Dunbar JD, Kessler KM, Baerwald MR, Jaffe EA, et al. Utilization of distinct signaling pathways by receptors for vascular endothelial cell growth factor and other mitogens in the induction of endothelial cell proliferation. J Biol Chem 2000; 275: 5096-103.

16 Fujio Y, Walsh K. Akt mediates cytoprotection of endothelial cells by vascular endothelial growth factor in an anchorage-dependent manner. J Biol Chem 1999; 274: 16349-54.

17 Shiojima I, Walsh K. Role of Akt signaling in vascular homeostasis and angiogenesis. Circ Res 2002; 90: 1243-50.

18 Rousseau S, Houle F, Landry J, Huot J. p38 MAP kinase activation by vascular endothelial growth factor mediates actin reorganization and cell migration in human endothelial cells. Oncogene 1997; 15: 2169-77.

19 Lv WW, Gao YJ, Su MZ, Luo Z, Zhang W, Shi GB, et al. Isoindolones from Lasiosphaera fenzlii Reich and their bioactivities. Helv Chim Acta 2013; 96: 109-13.

20 Qin SN, Lv WW, Wang Q, Zhao QC, Xu YN. Design, synthesis and biological evaluation of $\mathrm{N}$-substituted phthalimide derivative. Chem J Chinese U 2013; 34: 2745-51.

21 Nicoletti I, Migliorati G, Pagliacci MC, Grignani F, Riccardi C. A rapid and simple method for measuring thymocyte apoptosis by propidium iodide staining and flow cytometry. J Immunol Methods 1991; 139: 271-9.

22 Tang JY, Li S, Li ZH, Zhang ZJ, Hu G, Cheang D, et al. Calycosin promotes angiogenesis involving estrogen receptor and mitogenactivated protein kinase (MAPK) signaling pathway in zebrafish and HUVEC. PLoS One 2010; 5: e11822.

23 Slevin M, Kumar S, Gaffney J. Angiogenic oligosaccharides of hyaluronan induce multiple signaling pathways affecting vascular endothelial cell mitogenic and wound healing responses. J Biol Chem 2002; 277: 41046-59.

24 Zhao J, Zhao L, Chen W, He LC, Li X. Taspine downregulates VEGF expression and inhibits proliferation of vascular endothelial cells through PI3 kinase and MAP kinase signaling pathways. Biomed Pharmacother 2008; 62: 383-9.

25 Liu KK, He QX, Yuan YQ, Han LW, Peng WB, et al. Inventors; Biology Institute of Shandong Academy of Sciences, assignee. Methods of screening for anti-angiogenic active substances: CN102445531A. 2012 May 9.

26 Jendrossek V, Handrick R, Belka C. Celecoxib activates a novel mitochondrial apoptosis signaling pathway. FASEB J 2003; 17: 1547-9.

27 Jendrossek V, Muller I, Eibl H, Belka C. Intracellular mediators of erucylphosphocholine-induced apoptosis. Oncogene 2003; 22: 2621-31.

28 Engels IH, Stepczynska A, Stroh C, Lauber K, Berg C, Schwenzer $\mathrm{R}$, et al. Caspase-8/FLICE functions as an executioner caspase in anticancer drug-induced apoptosis. Oncogene 2000; 19: 4563-73.

29 Wieder T, Essmann F, Prokop A, Schmelz K, Schulze-Osthoff K, Beyaert R, et al. Activation of caspase-8 in drug-induced apoptosis of B-lymphoid cells is independent of CD95/Fas receptor-ligand interaction and occurs downstream of caspase-3. Blood 2001; 97: 1378-87.

30 Adams JM. Ways of dying: multiple pathways to apoptosis. Genes Dev 2003; 17: 2481-95.

31 Tavani A, La Vecchia C. Fruit and vegetable consumption and cancer risk in a Mediterranean population. Am J Clin Nutr 1995; 61: 1374S-1377S.

32 Patan S. Vasculogenesis and angiogenesis. Cancer Treat Res 2004; 117: 3-32.

33 Shibuya M. Vascular endothelial growth factor (VEGF)-receptor2: its biological functions, major signaling pathway, and specific ligand VEGF-E. Endothelium 2006; 13: 63-9.

34 Matsunaga N, Shimazawa M, Otsubo K, Hara H. Phosphatidylinositol 
inhibits vascular endothelial growth factor-A-induced migration of human umbilical vein endothelial cells. J Pharmacol Sci 2008 106: 128-35.

35 Fanelli M, Sarmiento R, Gattuso D, Carillio G, Capaccetti B, Vacca A. Thalidomide: a new anticancer drug. Expert Opin Investig Drugs 2003; 12: 1211-25.

36 Bauer KS, Dixon SC, Figg WD. Inhibition of angiogenesis by thalidomide requires metabolic activation, which is species-dependent. Biochem Pharmacol 1998; 55: 1827-34.

37 Marks MG, Shi J, Fry MO, Xiao Z, Trzyna M, Pokala V, et al. Effects of putative hydroxylated thalidomide metabolites on blood vessel density in the Chorioallantoic Membrane (CAM) assay and on tumor and endothelial cell proliferation. Biol Pharm Bull 2002; 25: 597-604.

38 Ng SS, Gutschow M, Weiss M, Hauschildt S, Teubert U, Hecker TK, et al. Antiangiogenic activity of $\mathrm{N}$-substituted and tetrafluorinated thalidomide analogues. Cancer Res 2003; 63: 3189-94.

39 Komorowski J, Jerczyńska H, Siejka A, Barańska P, Ławnicka H, Pawłowska Z, et al. Effect of thalidomide affecting VEGF secretion, cell migration, adhesion and capillary tube formation of human endothelial EA.hy 926 cells. Life Sci 2006; 78: 2558-63.

40 Morales-Ruiz M, Fulton D, Sowa G, Languino LR, Fujio Y, Walsh K, et al. Vascular endothelial growth factor-stimulated actin reorganization and migration of endothelial cells is regulated via the serine/ threonine kinase akt. Circ Res 2000; 86: 892-6.

41 Kureishi Y, Luo Z, Shiojima I, Bialik A, Fulton D, Lefer DJ, et al. The HMG-CoA reductase inhibitor simvastatin activates the protein kinase Akt and promotes angiogenesis in normo-cholesterolemic animals. Nat Med 2000; 6: 1004-10.

42 Dimmeler S, Dernbach E, Zeiher AM. Phosphorylation of the endothelial nitric oxide synthase at Ser-1177 is required for VEGF-induced endothelial cell migration. FEBS Lett 2000; 477: 258-62.

43 Franke TF, Hornik CP, Segev L, Shostak GA, Sugimoto C. PI3K/Akt and apoptosis: size matters. Oncogene 2003; 22: 8983-98.

44 Serra V, Markman B, Scaltriti M, Eichhorn PJ, Valero V, Guzman M, et al. NVP-BEZ235, a dual PI3K/mTOR inhibitor, prevents PI3K signaling and inhibits the growth of cancer cells with activating PI3K mutations. Cancer Res 2008; 68: 8022-30.

45 Zha J, Harada H, Yang E, Jockel J, Korsmeyer SJ. Serine phosphorylation of death agonist BAD in response to survival factor results in binding to 14-3-3 not BCL-XL. Cell 1996; 87: 619-28.

46 Hanahan D, Weinberg RA. The hallmarks of cancer. Cell 2000; 100 : 57-70.

47 Kim KH, Lee HJ, Jeong SJ, Lee HJ, Lee EO, Kim HS, et al. Galbanic acid isolated from Ferula assafoetida exerts in vivo anti-tumor activity in association with anti-angiogenesis and anti-proliferation. Pharm Res 2011; 28: 597-609. 